\title{
Revisited Role of B Cells in Atherosclerosis
}

\section{Paula Blair ${ }^{1}$ and Pasquale Maffia ${ }^{1,2 *}$}

${ }^{1}$ Institute of Infection, Immunity and Inflammation, University of Glasgow, Glasgow, UK ${ }^{2}$ Department of Experimental Pharmacology, University of Naples Federico II, Naples, Italy

B cells play a crucial role in both humoral and adaptive immune responses and are detectable in murine and human atherosclerotic arteries. Recent findings from mouse models are starting to re-define the complex role(s) of B-cells in the atherosclerosis. We will discuss the involvement of different B-cell subsets in vascular pathology and how B cells could be targeted for therapeutic utility.

Atherosclerosis-related cardiovascular diseases are the leading cause of mortality worldwide. Multiple leukocyte subsets have been shown to play a significant role in atherosclerosis $[1,2]$ and among them; $\mathrm{B}$ cells are receiving growing interest.

B cells play a crucial role in both humoral and adaptive immune responses. In addition to producing antibodies, B cells regulate T-cell responses via antigen presentation and cytokine production. Whilst it has been shown that patients with atherosclerosis produce antibodies against many antigens including oxidized low density lipoproteins (oxLDL), heat shock proteins (HSPs) and Chlamydia pneumoniae [3], the exact role of B cells in atherosclerosis has remained unclear, partly due to lack of knowledge on the existence of $B$ cell subsets in humans. However, B cell subsets have been well characterized in mice, and both B1 and B2 cells have been shown to play important roles in atherosclerosis. B1 cells constitute a small percentage of B lymphocytes; they are derived from fetal or neonatal precursors and are usually found in the pleural and peritoneal cavities. B1 cells differentiate into B1a and $\mathrm{B} 1 \mathrm{~b}$ cells with respect to $\mathrm{CD} 5$ expression. Their main role is in innate immune responses, where they are responsible for the production of the majority of serum IgM $[4,5]$. B2 cells are the main population of B cells in spleen and lymph nodes and are the key producers of adaptive IgG antibody after they have been activated by specific antigens and have differentiated into plasma cells. B2 cells also function as antigen presenting cells and cytokine producers; they are therefore able to modulate $\mathrm{T}$ cell responses $[4,5]$. The concept of a third subpopulation of $\mathrm{B}$ cells with regulatory properties (Breg) was only recently introduced. A clear phenotypical characterization of Bregs is lacking, therefore all the B-cell subsets acting as immune regulators via IL-10 production are generally referred to as B10 cells [6]. Both natural and adaptive antibody responses are involved in atherosclerosis, as shown by the presence of IgM and IgG in atherosclerotic plaques [7,8].

$B$ cells are found in atherosclerotic lesions in mice [9] and in humans [10]. In addition, B cells are present in the adventitia of normal and atherosclerotic arteries [11-13] and represent the major cells populating aortic tertiary lymphoid organs in aged apolipoprotein $\mathrm{E}$ deficient (apoE-/-) mice [14]. The role that B cells play in atherosclerosis has been the source of conflict in recent years, with studies by several groups pointing to an atheroprotective role for the cells, whilst others have demonstrated a pro-atherogenic function [15].

Key studies showing the protective role of $\mathrm{B}$ cells have been carried out by Caligiuri et al. [3] and Major et al. [16], using different mouse models of atherosclerosis. Caligiuri et al. [3] studied spleen associated immune activity in apoE-/- mice. The authors initially showed that splenectomy dramatically aggravated atherosclerosis in hypercholesterolemic apoE-/- mice and that the transfer of spleen cells from atherosclerotic apoE-/- mice significantly decreased development of atherosclerosis in young apoE-/- recipients. To identify which lymphocyte subset was immunoprotective, the group performed immunomagnetic separation before cell transfer to separate the $\mathrm{T}$ and $\mathrm{B}$ cells. They found that the B cells were conferring protection to atherosclerosis and were able to reduce disease in splenectomised apoE-/- mice. This protective effect was associated with an increase in antibody titers to oxLDL. Overall, these findings implied that $\mathrm{B}$ cells were playing a protective role in atherosclerosis [3]. Work by Major et al. [16] reached similar conclusions. The group used B-cell deficient $(\mu \mathrm{MT})$ mice as bone marrow donors for irradiated low density lipoprotein receptor deficient (LDLR-/-) mice; recipients were subsequently shown to have $<1 \%$ of their normal B cell population. The B cell deficient LDLR-/-) mice on a high fat diet had a marked decrease in their total serum antibody levels, and also in their antibody levels against ox-LDL. Furthermore, B cell deficiency was associated with a $30-40 \%$ increase in the lesion area [16]. These results again show a protective role for $\mathrm{B}$ cells in atherosclerosis.

Recently, the paradigm of protective B cells was challenged by AitOufella et al. [17] who examined lesion development in mice with or without B cell depletion via a CD20 monoclonal antibody, previously validated [18]. They began by studying apoE-/- mice fed a high fat western diet. The mice were treated with CD20 monoclonal antibody, which led to a sustained and profound decrease in the number of mature B cells in the blood, spleen, bone marrow and peritoneum. The group expected to see an exacerbation of atherosclerosis, however, they saw a significant reduction in lesion development. To rule out the possibility that this effect was due to the particular mouse model and diet, the group performed the same experiments on apoE-/- mice fed a chow diet, and also on LDLR-/- mice; again, they found that treatment with CD20 monoclonal antibody led to marked B cell depletion and to a significant decrease in atherosclerosis [17]. This B2 cell depletion was associated with decreased activated splenic CD4+ T cells, T-cell proliferation, and lesional $\mathrm{T}$ cell content. These results suggest a proatherogenic role for B cells which had previously been unknown.

These discrepancies may relate to the subsets of B cells involved in atherosclerosis, particularly with regards to their role as antibody

*Corresponding author: Pasquale Maffia, Institute of Infection, Immunity and Inflammation, College of Medical, Veterinary and Life Sciences, University of Glasgow, 120 University Place, Glasgow G128TA, UK, Tel: +44 (0)141 330 7142; E-mail: Pasquale.Maffia@glasgow.ac.uk

Received October 08, 2012; Accepted October 27, 2012; Published October 28 2012

Citation: Blair P, Maffia P (2012) Revisited Role of B Cells in Atherosclerosis. Pharmaceut Anal Acta 3:174. doi:10.4172/2153-2435.1000174

Copyright: (C) 2012 Blair P, et al. This is an open-access article distributed unde the terms of the Creative Commons Attribution License, which permits unrestricted use, distribution, and reproduction in any medium, provided the original author and source are credited. 
producers. Numerous studies in humans have shown that the relationship between IgM anti-oxLDL levels and cardiovascular disease outcome are inversely correlated, whereas high IgG anti-oxLDL levels were positively associated with clinical cardiovascular events [19-21]. Furthermore, high levels of IgM anti- oxLDL are associated with a stable atherosclerotic plaque phenotype containing fewer macrophages and more extracellular matrix (ECM); high levels of IgG against oxLDL are related to an unstable plaque phenotype containing increased lipids and decreased ECM [22]. Overall, these data contribute to the hypothesis that IgM is playing a protective role in atherosclerosis whilst the IgG response is pro-atherogenic.

It is also possible that the methods used to study B cell depletion can impact on atherosclerotic outcome. Whilst splenectomy and the use of $\mu \mathrm{MT}$-deficient mice investigated the role of depletion of $\mathrm{B}$ cells without regards to maturation state, use of the monoclonal CD20 antibody investigated the depletion of the mature B cell population [17]. Serum level of natural IgM antibody remained unchanged following B cell depletion, due the minimal depletion of peritoneal B1a cells. On the contrary, IgG antibodies against oxLDL were significantly decreased [17].

Interestingly, the direct contribution of different B-cell subsets to the pathology has been recently investigated. Kyaw et al. [23] showed that adoptive transfer of B2 cells (but not B1 cells) increased atherosclerosis in B-cell deficient $(\mu \mathrm{MT})$ apoE-/- mice, confirming a pro- atherogenic role of this B2-cell subset $[17,23]$. The use of chimeric mice of mixed genotype (transfer of apoE $+/+\mathrm{C} 57 \mathrm{BL} / 6 \mathrm{~B}$ cells into $\mu \mathrm{MT}$ apoE-/-) may confound interpretation of these data. However, Sage et al. [24] presented another important study confirming the impact of B2 cells on atherosclerosis by using a genetic strategy of B cell activating factor receptor (BAFFR) deficiency to deplete B2 cells. BAFFR is a tumor necrosis factor receptor family member that is critical for maintaining mature B2 B cells. The authors reconstituted lethally irradiated LDLr-/- mice with either wild type or BAFFRdeficient bone marrow. BAFFR deficiency in bone marrow cells led to a marked reduction of conventional mature B2 cells but did not affect the B1a cell subtype. This was associated with a significant reduction of dendritic cell activation, T-cell proliferation, IgG antibodies against malondialdehyde- modified LDL along with a significant reduction in atherosclerotic lesion development. Consistent with these findings Kyaw et al. [25] recently demonstrated that depletion of B2 cells in BAFFR-deficient apoE-/- double KO mice reduced lesion formation and vascular inflamation Taken together, these studies clearly demonstrate a pro-atherogenic role for B2 cells. On the contrary B1a cells have been show to be atheroprotective [26]. Splenectomy of apoE-/- mice reduced peritoneal B1a cells, plasma IgM, oxLDL IgM and lesional IgM levels, which was accompanied by increased atherosclerotic lesion size, necrotic core, lesional oxLDL and apoptotic cells. These effects were reversed upon transfer of B1a cells. The authors showed that the protective effects of the B1a-cell subset were mediated by IgM secretion [26].

Yet several important questions remain unanswered. Are IL-10 producing Bregs atheroprotective? What are the mechanisms whereby B-cell subsets influence atherosclerosis? Recently, an atheroprotective role for B cells homing the aorta has been described [13]. Which is net contribution of splenic $v s$ arterial B cells to the pathology? And which $\mathrm{B}$-cell subsets are predominant in healthy $v s$ atherosclerotic vessels?
Answers to these questions would have important therapeutic implications. The therapies availabletoday for preventing coronaryartery disease and stroke rely almost exclusively on risk factor intervention, whereas therapies directly targeting vascular inflammation are lacking. $B$ cell depletion appears as an effective therapy in many autoimmune diseases including rheumatoid arthritis (RA) however, research on cardiovascular effects of the chimeric antiCD20 monoclonal antibody (rituximab, RTX) has produced controversial results to date [27]. In a small clinical pilot study favorable effects are RTX on the lipidprofile, endothelial function and carotid intima/media thickness in RA patients have been reported [28]. However, the small number of patients analyzed in this study may confound interpretation. More recently, no significant change in arterial stiffness in RA patients after 6 months and 1 year of rituximab treatment was observed [29]. Unexpectedly, a reduced efficacy of RTX has been observed when administered with statins [30].

In conclusion, with regard to approaches aiming at B cell targeting it will be essential to develop B cell subset specific strategies that deplete B2 cells but do not affect B1a and regulatory B10 cells. Little is known about the effect of $B$ cell targeting therapy in humans on different $B$ cell subsets and therefore B cell therapy is still far away from clinical practice for atherosclerosis.

\section{Conflicts of Interest}

The authors declare no conflicts of interest that may have influenced the discussion therein.

\section{References}

1. Galkina E, Ley K (2009) Immune and inflammatory mechanisms of atherosclerosis $\left(^{*}\right)$. Annu Rev Immunol 27: 165-197.

2. Libby P, Ridker PM, Hansson GK (2011) Progress and challenges in translating the biology of atherosclerosis. Nature 473: 317-325.

3. Caligiuri G, Nicoletti A, Poirier B, Hansson GK (2002) Protective immunity against atherosclerosis carried by $\mathrm{B}$ cells of hypercholesterolemic mice. J Clin Invest 109: 745-753

4. DiLillo DJ, Matsushita T, Tedder TF (2010) B10 cells and regulatory B cells balance immune responses during inflammation, autoimmunity, and cancer Ann N Y Acad Sci 1183: 38-57.

5. DiLillo DJ, Horikawa M, Tedder TF (2011) B-lymphocyte effector functions in health and disease. Immunol Res 49: 281-292.

6. Vitale G, Mion F, Pucillo C (2010) Regulatory B cells: evidence, developmental origin and population diversity. Mol Immunol 48: 1-8

7. Ylä-Herttuala S, Palinski W, Butler SW, Picard S, Steinberg D, et al. (1994) Rabbit and human atherosclerotic lesions contain IgG that recognizes epitopes of oxidized LDL. Arterioscler Thromb 14: 32-40.

8. Van Leeuwen M, Damoiseaux J, Duijvestijn A, Tervaert JW (2009) The therapeutic potential of targeting $B$ cells and anti-oxLDL antibodies in atherosclerosis. Autoimmun Rev 9: 53-57.

9. Zhou X, Hansson GK (1999) Detection of B cells and proinflammatory cytokines in atherosclerotic plaques of hypercholesterolaemic apolipoprotein $\mathrm{E}$ knockout mice. Scand J Immunol 50: 25-30

10. Aubry MC, Riehle DL, Edwards WD, Maradit-Kremers H, Roger VL, et al. (2004) B- Lymphocytes in plaque and adventitia of coronary arteries in two patients with rheumatoid arthritis and coronary atherosclerosis: preliminary observations. Cardiovasc Pathol 13: 233-236.

11. Galkina E, Kadl A, Sanders J, Varughese D, Sarembock IJ, et al. (2006) Lymphocyte recruitment into the aortic wall before and during development of atherosclerosis is partially L-selectin dependent. J Exp Med 203: 1273-1282.

12. Macritchie N, Grassia G, Sabir SR, Maddaluno M, Welsh P, et al. (2012) 
Plasmacytoid Dendritic Cells Play a Key Role in Promoting Atherosclerosis in Apolipoprotein E- Deficient Mice. Arterioscler Thromb Vasc Biol 32: 2569-2579.

13. Doran AC, Lipinski MJ, Oldham SN, Garmey JC, Campbell KA, et al. (2012) B-cell aortic homing and atheroprotection depend on Id3. Circ Res 110: 1-12.

14. Gräbner R, Lötzer K, Döpping S, Hildner M, Radke D, et al. (2009) Lymphotoxin beta receptor signaling promotes tertiary lymphoid organogenesis in the aorta adventitia of aged ApoE-/- mice. J Exp Med 206: 233-248.

15. Perry HM, McNamara CA (2012) Refining the Role of B Cells in Atherosclerosis. Arterioscler Thromb Vasc Biol 32: 1548-1549.

16. Major AS, Fazio S, Linton MF (2002) B-lymphocyte deficiency increases atherosclerosis in LDL receptor-null mice. Arterioscler Thromb Vasc Biol 22: 1892-1898.

17. Ait-Oufella H, Herbin O, Bouaziz JD, Binder CJ, Uyttenhove C, et al. (2010) B cell depletion reduces the development of atherosclerosis in mice. J Exp Med 207: 1579-1587.

18. Uchida J, Lee Y, Hasegawa M, Liang Y, Bradney A, et al. (2004) Mouse CD20 expression and function. Int Immunol 16: 119-129.

19. Hulthe J, Bokemark L, Fagerberg B (2001) Antibodies to oxidized LDL in relation to intima-media thickness in carotid and femoral arteries in 58-year-old subjectively clinically healthy men. Arterioscler Thromb Vasc Biol 21: 101-107.

20. Karvonen J, Paivansalo M, Kesaniemi YA, Horkko S (2003) Immunoglobulin $M$ type of autoantibodies to oxidized low-density lipoprotein has an inverse relation to carotid artery atherosclerosis. Circulation 108: 2107-2112.

21. Tsimikas S, Brilakis ES, Lennon RJ, Miller ER, Witztum JL, et al. (2007) Relationship of $\lg$ and IgM autoantibodies to oxidized low density lipoprotein with coronary artery disease and cardiovascular events. J Lipid Res 48: 425433.

22. Goncalves I, Gronholdt ML, Soderberg I, Ares MP, Nordestgaard BG, et al. (2005) Humoral immune response against defined oxidized low-density lipoprotein antigens reflects structure and disease activity of carotid plaques. Arterioscler Thromb Vasc Biol 25: 1250-1255.

23. Kyaw T, Tay C, Khan A, Dumouchel V, Cao A, et al. (2010) Conventiona B2 B cell depletion ameliorates whereas its adoptive transfer aggravates atherosclerosis. J Immunol 185: 4410-4419.

24. Sage AP, Tsiantoulas D, Baker L, Harrison J, Masters L, et al. (2012) BAFF receptor deficiency reduces the development of atherosclerosis in mice--brief report. Arterioscler Thromb Vasc Biol 32: 1573-1576.

25. Kyaw T, Tay C, Hosseini H, Kanellakis P, Gadowski T, et al. (2012) Depletion of B2 but not B1a B cells in BAFF receptor-deficient ApoE mice attenuates atherosclerosis by potently ameliorating arterial inflammation. PLoS One 7: 29371.

26. Kyaw T, Tay C, Krishnamurthi S, Kanellakis P, Agrotis A, et al. (2011) B1a B lymphocytes are atheroprotective by secreting natural IgM that increases IgM deposits and reduces necrotic cores in atherosclerotic lesions. Circ Res 109: 830-840.

27. Novikova DS, Popkova TV, Nasonov EL (2012) The effect of anti-B-cell therapy on the development of atherosclerosis in patients with rheumatoid arthritis. Curr Pharm Des 18: 1512-1518.

28. Kerekes G, Soltesz P, Der H, Veres K, Szabo Z, et al. (2009) Effects of rituximab treatment on endothelial dysfunction, carotid atherosclerosis, and lipid profile in rheumatoid arthritis. Clin Rheumatol 28: 705-710.

29. Mathieu S, Pereira B, Dubost JJ, Lusson JR, Soubrier M (2012) No significant change in arterial stiffness in RA after 6 months and 1 year of rituximab treatment. Rheumatology (Oxford) 51: 1107-1111.

30. Arts EE, Jansen TL, Den Broeder A, Vonkeman HE, Dutmer E, et al. (2011) Statins inhibit the antirheumatic effects of rituximab in rheumatoid arthritis: results from the Dutch Rheumatoid Arthritis Monitoring (DREAM) registry. Ann Rheum Dis 70: 877-878. 